\title{
Prophylactic use of IV atropine for prevention of spinal anesthesia induced hypotension and bradycardia in elderly: a randomized controlled trial
}

\author{
Shailendra Sigdel
}

Correspondence: sigdelshailendra@gmail.com

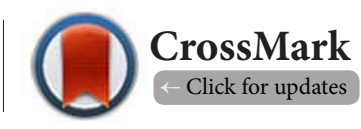

Department of Anesthesiology, Manmohan Cardiothoracic Vascular and Transplant Center, Institute of Medicine, Tribhuvan University, Kathmandu, Nepal.

\begin{abstract}
Background: Spinal anesthesia induced hypotension is common and hazardous in elderly patients. Reversal of the blunted reflexes of tachycardia following hypotension in elderly with atropine helps in prevention of spinal anesthesia induced hypotension in elderly.

Methodology: In this randomized, double-blind, controlled trial forty ASA PS I to II patients undergoing urological surgeries were assigned to receive either IV normal saline (placebo) or IV atropine 0.6 mg one minute after the induction of spinal anesthesia. Heart rate (HR), mean arterial pressure (MAP), requirement for mephentermine or phenylephrine, and the side effects profile were studied intra/postoperatively for 6 hours.

Results: The patients were comparable with respect to demographic profile, baseline hemodynamic parameters, and the duration of surgery. Compared to baseline, mean HR and MAP were significantly reduced in the placebo group most of the study times $(p<0.05)$. The incidence of hypotension was high in placebo $(60 \%)$ compared to the atropine group $(5 \%)$. Thus, the requirement of mephentermine for the management of hypotension was significantly higher $(\mathrm{p}<0.001)$ in the placebo group $(60 \%)$ than the atropine group (5\%).
\end{abstract}

Conclusion: Intravenous administration of atropine $0.6 \mathrm{mg}$, one min after the induction of spinal anesthesia in an elderly patient, is a safe and effective method in the prevention of spinal anesthesia induced hypotension and bradycardia.

Keywords: Spinal anesthesia, hypotension, atropine, bradycardia

\section{Introduction}

The most common and the most serious side effects of spinal anesthesia are hypotension (33\%) and bradycardia (13\%) $[1,2]$. Systemic vasodilation induced by sympathetic blockade after spinal anesthesia (SA), resulting in venous pooling of blood and reduction in systemic vascular resistance, has been regarded as the predominant mechanism for hypotension. In addition, the blunted reflex tachycardia following hypotension in elderly also play important role in the persistence of hypotension [3]. This phenomenon may result from the blockade of cardioaccelerator sympathetic fibers at T1 to T4, and possibly the "reverse" of the Bainbridge reflex. The Bainbridge reflex, also called atrial reflex, is increase of the heart rate resulting from distension of large systemic veins or the right atrium. This reflex was first described by the British physiologist Francis Arthur Bainbridge in 1915, and was believed to prevent the pooling of blood in the venous system. Special pressure sensors called baroreceptors (or venoatrial stretch receptors) located in the right atrium of the heart detect increases in the volume and pressure of blood returned to the heart. These receptors transmit information along the vagus nerve $\left(10^{\text {th }}\right.$ cranial nerve) to the central nervous system. This response results in the activation of sympathetic nerve pathways that serve to increase the strength of contraction of the heart muscle and to increase heart rate (tachycardia). Caplan et al., [4] postulated that in the setting of spinal anesthesia reduced atrial filling and unopposed vagal tone produces a sufficient degree of bradycardia and hypotension, resulting in cardiac arrest. The present study considers that the reduction of reflex tachycardia following hypotension is an important component in the pathogenesis of persistence 
hypotension in elderly patient, in addition, to the effects of venous and arterial dilation, and the null hypothesis is that this effect can be mitigated with atropine.

The rational of choosing atropine was that elderly have blunted cardiac reflexes. The prophylactic use of atropine helps in preventing the blunted reflexes, thus, helping in increasing heart rate and cardiac output, and finally blood pressure. The primary outcome of the present study was to compare the heart rate and mean arterial pressure after SA in groups treated and not treated with atropine. Secondary data gathered was the requirement of vasopressor, and occurrence of other adverse effects following SA in groups treated and not treated with atropine.

\section{Methods}

Institutional review board (IRB) at Tribhuvan University Teaching Hospital (TUTH) approved this prospective, randomized, double blind controlled study. Oral and written informed consent was obtained from each patient to enroll in the study. The sample size was based on the number during the previous year where patients aged more than 60 years underwent urological surgeries under spinal anesthesia in the Department of Anesthesiology at TUTH. A size of 20 patients per group was required to attain a power of $80 \%$ and type I error of 0.05 . The inclusion criteria were age more than 60 years, scheduled for urological surgery under spinal anesthesia, and American Society of Anesthesiologist physical status Physical Status (ASA PS) I-II. Patients with arrhythmia or conduction abnormality, hypertension (systolic blood pressure more than $140 \mathrm{~mm} \mathrm{Hg}$ or diastolic blood pressure more than $90 \mathrm{~mm} \mathrm{Hg}$ ), unstable angina or cardiomyopathy, patients taking $\beta$-adrenergic blockers or any drugs that may alter normal response to study drugs were excluded from the study. After pre-anesthetic evaluation patients were randomized to one of the two groups, using a computer generated random number table, to receive either normal saline (Group N) or atropine 0.6mg (Group A). All drugs were made in a volume of $2.5 \mathrm{ml}$ in a similar looking syringe and they were administered to the patient one minute after the induction of spinal anesthesia as per the group allocation.

Patients were premedicated with midazolam $7.5 \mathrm{mg}$ per oral two hours before surgery. In the preanesthetic preparation room, each patient was preloaded with normal saline (NS) 10 $\mathrm{ml} / \mathrm{kg} 20$ minutes before the induction of spinal anesthesia. In operating room, patient was monitored for heart rate, non-invasive blood pressure, arterial oxygen saturation and electrocardiogram until the completion of surgery. Subarachnoid block was performed at the L3-L4 space with $2.5 \mathrm{ml}$ of $0.5 \%$ hyperbaric bupivacaine with the patient in the sitting position, and then the patient was immediately placed in the supine position. After one minute, one of the study drugs was injected intravenously. MAP and $\mathrm{HR}$ were recorded at 0 (baseline), 1, 5, 10, 20, 30, 40, 50 and 60 minutes following the administration of study drugs.
Clinically significant hypotension was defined as systolic blood pressure of $<90 \mathrm{~mm} \mathrm{Hg}$ and was treated with mephentermine $6 \mathrm{mg}$ IV and repeated as needed. Phenylepherine $50 \mathrm{mcg}$ IV was administered as a rescue drug if more than $30 \mathrm{mg}$ of inj. mephentermine was required to restore the systolic blood pressure to over $90 \mathrm{mmHg}$. Bradycardia (HR<50 bpm) was treated with atropine $0.6 \mathrm{mg}$ IV. Tachycardia (HR $>140 / \mathrm{min}$ ) was treated with intermittent boluses of esmolol $10 \mathrm{mg} \mathrm{IV}$ as needed. Hypertension (SBP more than $160 \mathrm{mmHg}$ or DBP more than $100 \mathrm{mmHg}$ ) was also treated with boluses of esmolol $10 \mathrm{mg}$ IV as needed.

The amount of vasopressor (mephentermine or phenylephrine) administered, sensory level of anesthesia achieved at 15 minutes, and the clinical side effects such as angina or confusion were recorded untill 6 hours after the procedure was completed.

Data were collected as per the proforma. For the analysis of the data Statistical Package for the Social Sciences (SPSS) 17 was used. $P$ values $<0.05$ were considered as statistically significant.

\section{Results}

All forty patients enrolled completed the study. Demographic data (Age, Weight, ASA PS, and Diagnosis) in the both groups were comparable as shown in Table 1. There were no differences regarding demographics and type of surgeries in both groups. The types of surgeries were transurethral resection under spinal anesthesia for benign prostate enlargement (BEP) or carcinoma of the bladder.

As compared to the baseline, mean heart rate was increased in Group A at 1, 5, 10, 15, 20 and 30 minutes (Table 2). Maximum heart rate in Group A was $89.30 \pm 14.62$ bpm at five minutes. In contrast, HR significantly decreased in Group $\mathrm{N}$ at 30, 40, 50 and 60 minutes with minimum mean HR of $65.40 \pm 11.34 \mathrm{bpm}$. In group N, $40 \%$ of the patients required atropine for the treatment of bradycardia, which was statistically significant ( $p=0.01$ ) (Table 4).

As compared to baseline, MAP didn't change significantly in Group A except at one minute (Table 3). However, in group N, MAP significantly decreased all the times measured except at one minute (Table 3 ) and treatment was required in $40 \%$ of the cases (Table 4 ).

Table 1. Demographic data.

\begin{tabular}{llll}
\hline & $\begin{array}{l}\text { Group A } \\
(\mathbf{n = 2 0})\end{array}$ & $\begin{array}{l}\text { Group B } \\
(\mathbf{n = 2 0})\end{array}$ & P-value \\
\hline Age (yrs.) & $70.00 \pm 7.90$ & $69.85 \pm 8.09$ & 0.79 \\
Weight (Kg) & $60.00 \pm 10.31$ & $59.50 \pm 6.62$ & 0.91 \\
Baseline (HR) & $73.60 \pm 10.30$ & $71.35 \pm 7.70$ & 0.75 \\
Baseline (MAP) & $97.88 \pm 6.70$ & $92.38 \pm 9.23$ & 0.10 \\
Duration (Min) & $70.85 \pm 7.92$ & $72.55 \pm 6.45$ & 0.46 \\
\hline
\end{tabular}

Data described as mean $\pm \mathrm{SD}$;

${ }^{*} \mathrm{p}<0.05$ considered statistically significant.

MAP: Mean arterial pressure; SD: Standard deviation 
Shailendra Sigdel, Journal of Anesthesiology \& Clinical Science 2015, http://www.hoajonline.com/journals/pdf/2049-9752-4-5.pdf

Table 2. Comparison of mean HR with baseline in each group.

\begin{tabular}{lllll}
\hline & Group A $(\mathbf{n}=\mathbf{2 0})$ & P-value & Group N $(\mathbf{n = 2 0})$ & P-value \\
\hline HR 0 & $73.60 \pm 10.30$ & -- & $71.35 \pm 7.70$ & -- \\
HR 1 & $83.35 \pm 14.13$ & $0.00^{*}$ & $71.45 \pm 9.74$ & 0.88 \\
HR 5 & $88.95 \pm 14.62$ & $0.00^{*}$ & $68.95 \pm 10.07$ & 0.15 \\
HR 10 & $85.40 \pm 13.18$ & $0.00^{*}$ & $67.60 \pm 9.95$ & 0.08 \\
HR 15 & $83.80 \pm 14.35$ & $0.00^{*}$ & $68.05 \pm 9.82$ & 0.11 \\
HR 20 & $82.30 \pm 13.56$ & $0.00^{*}$ & $69.00 \pm 13.95$ & 0.25 \\
HR 30 & $80.95 \pm 13.53$ & $0.01^{*}$ & $65.95 \pm 11.03$ & $0.01^{*}$ \\
HR 40 & $76.20 \pm 13.31$ & 0.47 & $65.40 \pm 11.34$ & $0.01^{\star}$ \\
HR 50 & $76.30 \pm 9.56$ & 0.25 & $65.80 \pm 10.66$ & $0.04^{\star}$ \\
HR 60 & $76.20 \pm 12.91$ & 0.50 & $66.25 \pm 10.47$ & $0.02^{*}$ \\
\hline
\end{tabular}

Data described as mean \pm SD;

${ }^{*} \mathrm{p}<0.05$ considered statistically significant.

MAP: Mean arterial pressure; SD: Standard deviation

Table 3. Comparison of mean MAP with baseline in each group.

\begin{tabular}{lllll}
\hline & Group A $(\mathbf{n}=20)$ & P-value & Group N (n=20) & P-value \\
\hline MAP 0 & $97.88 \pm 6.70$ & -- & $92.38 \pm 9.23$ & -- \\
MAP 1 & $103.17 \pm 8.87$ & $0.01^{*}$ & $91.10 \pm 11.30$ & 0.24 \\
MAP 5 & $99.80 \pm 10.74$ & 0.31 & $76.92 \pm 11.60$ & $0.00^{*}$ \\
MAP 10 & $98.80 \pm 8.27$ & 0.81 & $81.43 \pm 13.68$ & $0.00^{*}$ \\
MAP 15 & $97.00 \pm 8.16$ & 0.56 & $85.00 \pm 10.79$ & $0.00^{*}$ \\
MAP 20 & $95.73 \pm 11.68$ & 0.37 & $82.40 \pm 10.48$ & $0.00^{*}$ \\
MAP 30 & $94.88 \pm 10.70$ & 0.12 & $82.92 \pm 10.30$ & $0.00^{*}$ \\
MAP 40 & $96.30 \pm 9.51$ & 0.48 & $82.60 \pm 10.81$ & $0.00^{*}$ \\
MAP 50 & $94.40 \pm 9.41$ & 0.09 & $84.42 \pm 9.84$ & $0.00^{*}$ \\
MAP 60 & $95.10 \pm 9.36$ & 0.13 & $83.20 \pm 9.40$ & $0.00^{*}$ \\
\hline
\end{tabular}

Data described as mean \pm SD;

${ }^{*} \mathrm{p}<0.05$ considered statistically significant.

MAP: Mean arterial pressure; SD: Standard deviation

Table 4. Intra operative events.

\begin{tabular}{llll}
\hline & $\begin{array}{l}\text { Group A } \\
(\mathbf{n = 2 0 )}\end{array}$ & $\begin{array}{l}\text { Group N } \\
(\mathbf{n = 2 0 )}\end{array}$ & P-value \\
\hline Mephentermine used & $1(5 \%)$ & $12(60 \%)$ & $0.01^{*}$ \\
Bradycardia & 0 & $8(40 \%)$ & $0.01^{*}$ \\
Tachycardia & $1(5 \%)$ & $0(0 \%)$ & 0.48 \\
Other adverse effects & 0 & 0 & -- \\
\hline
\end{tabular}

Data described as number (percentage),

${ }^{*} \mathrm{p}<0.05$ considered statistically significant.

Comparing the groups, the heart rate was significantly higher in the atropine group as compared to placebo group at 1,5, 10 and 15 minutes. Whereas at 20,30, 40, 50 and 60 minutes $\mathrm{HR}$ was significantly lower in the placebo group (Figure 1).
Comparing the groups, MAP was significantly high in the atropine group as compared to the placebo group at one minute. Whereas at 5, 10, 15, 20,30,40,50 and 60 minutes MAP was lower in the placebo group compared to the atropine group (Figure 2).

Intraoperatively, $60 \%$ of patients developed hypotension $(p=0.01)$ and $40 \%$ developed bradycardia $(p=0.01)$ in the placebo group, all of whom required treatment; this was statistically significant as compared to the atropine group (Table 4). None of the patients in either group developed other clinical side effects like angina or confusion during the six hours they were observed postoperatively. No other side effects were detected in any of the groups.
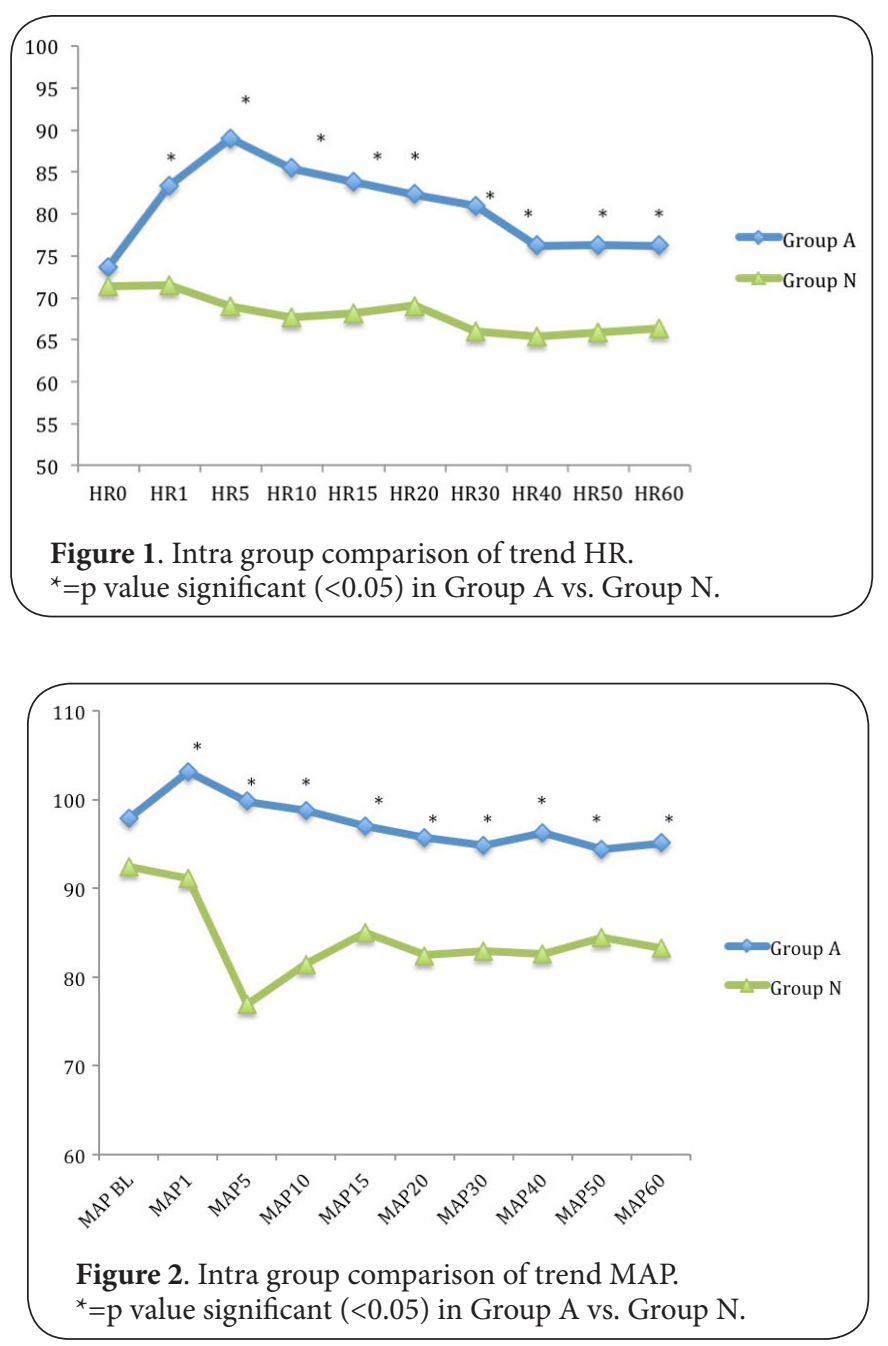

\section{Discussion}

The most common and serious side effects from spinal anesthesia are hypotension and bradycardia $[1,2]$ and closed claims surveys of 40,000-550,000 spinal anesthetics indicate an incidence of cardiac arrest from $0.04-1 / 10,000[5,6]$. Risk factors for hypotension are a sympathetic block height T5 or higher, age 40 years or older, baseline systolic blood pres- 
sure less than $120 \mathrm{mmHg}$, and subarachnoid puncture site above L3-L4. Risk factors for development of bradycardia include baseline heart rate less than $60 \mathrm{bpm}$, ASA PS I, use of $\beta$-adrenergic blockers, prolonged PR interval on electrocardiogram, and block height T5 or higher $[1,7]$.

Currently various techniques are advocated for the prevention of hypotension and bradycardia which include pre or co-loading of IV fluid, vasopressors, and physical methods such as table tilt, leg binders, and compression devices [8-14]. However, a Cochrane review concluded that none of these techniques alone is reliably effective and suggested that the future research be directed towards identifying a combination of interventions which more reliably prevent hemodynamic compromise [11]. This study demonstrated that hypotension associated with spinal anesthesia for urologic surgery could be mitigated with combination of preloading with normal saline $10 \mathrm{ml} / \mathrm{kg}$ and pretreatment with IV atropine.

Atropine is an ester of an aromatic acid combined with an organic base. It competitively blocks acetylcholine binding to the cholinergic receptor and in the heart prevents muscarinic receptor activation by acetylcholine, increasing heart rate by abolishing vagal tone.

The findings of the study were are similar to various other studies. IV atropine after a crystalloid infusion in patients undergoing SA could increase HR very quickly in a dosedependent manner and decrease the incidence of significant hypotension also in a dose-dependent manner [15]. PUN Nze [16] demonstrated the incidence and severity of hypotension were reduced in parturients undergoing cesarean section under spinal anesthesia with use of prophylactic intravenous bolus of atropine. Thus intravenous atropine may be a useful supplement to the existing methods in preventing hypotension induced by spinal anesthesia. Intramuscular atropine has also been studied, but Hirabayashi et al., [17] did not demonstrate any beneficial effect in hemodynamic stability during SA because the absorption of IM atropine may be unpredictable, and the onset may have been too slow in comparison to the onset of hypotension after SA. Another anticholinergic agent, glycopyrrolate, when administered IV after SA increased HR and reduced the severity of hypotension [18] in women presenting for elective cesarean section, reducing ephedrine requirements $(p=0.002)$.

Though our study didn't show any significant side effects in intra/post operative period (Table 4) many practitioners hesitate to administer atropine as it crosses the blood brain barrier and may be associated with adverse CNS effects. Glycopyrrolate may be similarly effective in preventing SA induced hypotension and bradycardia but it cannot be concluded from the present study and further investigation is required.

In summary, hypotension and bradycardia after induction of spinal anesthesia were common in elderly patients. The use of IV atropine one minute after the induction of spinal anesthesia in elderly patients was beneficial in maintaining hemodynamic stability. Although, the heart rate was higher in the atropine group, the incidence of clinically significant tachycardia (HR>140 bpm) was trivial. No patients in either group developed other side effects. So, the study suggested prophylactic IV atropine can be safely used in elderly patients for the prevention of spinal anesthesia induced hypotension and bradycardia.

\section{Limitations}

Amount of blood loss, which could influence the hemodynamic parameters, was not recorded in the study. For the measurement of blood pressure, oscillatory noninvasive blood pressure monitoring was used; invasive blood pressure monitoring might have revealed more nuanced data. Only the patients having transurethral urological surgeries (TURP, CA UB) were studied, which required spinal anesthesia levels of T10 or below for surgery. The population studied might not be the actual representative of the SA induced hypotension associated with higher blocks more than T10.

\section{Conclusions}

The use of prophylactic IV atropine after one minute of induction of spinal anesthesia reduces the incidence and severity of the spinal anesthesia induced hypotension as well as the incidence of bradycardia in elderly patients. The need of vasopressors also decreases significantly.

\section{Competing interests}

The author declares that he has no competing interests.

\section{Acknowledgement}

I would like to acknowledge all the faculties, senior and junior colleagues, and the technical staffs of Department of Anesthesiology in Tribhuvan University Teaching Hospital who directly or indirectly helped me conducting the research.

\section{Publication history}

Editor: Gerald A. Bushman, Childrens Hospital Los Angeles, USA. Received: 02-Aug-2015 Final Revised: 28-Sep-2015

Accepted: 19-Oct-2015 Published: 29-Oct-2015

\section{References}

1. Carpenter RL, Caplan RA, Brown DL, Stephenson C and Wu R. Incidence and risk factors for side effects of spinal anesthesia. Anesthesiology. 1992; 76:906-16. | Article I PubMed

2. Arndt JO, Bomer W, Krauth J and Marquardt B. Incidence and time course of cardiovascular side effects during spinal anesthesia after prophylactic administration of intravenous fluids or vasoconstrictors. Anesth Analg. 1998; 87:347-54. I Article I PubMed

3. Dobson PM, Caldicott LD, Gerrish SP, Cole JR and Channer KS. Changes in haemodynamic variables during transurethral resection of the prostate: comparison of general and spinal anaesthesia. Br J Anaesth. 1994; 72:267-71. | Article I PubMed

4. Caplan RA, Ward RJ, Posner K and Cheney FW. Unexpected cardiac arrest during spinal anesthesia: a closed claims analysis of predisposing factors. Anesthesiology. 1988; 68:5-11. I Article I PubMed

5. Auroy Y, Narchi P, Messiah A, Litt L, Rouvier B and Samii K. Serious complications related to regional anesthesia: results of a prospective survey in France. Anesthesiology. 1997; 87:479-86. I Article I PubMed

6. Aromaa U, Lahdensuu M and Cozanitis DA. Severe complications as- 
sociated with epidural and spinal anaesthesias in Finland 1987-1993. A study based on patient insurance claims [see comment]. Acta Anaesthesiol Scand. 1997; 41:445-52. | Article | PubMed

7. Liu S, Paul GE, Carpenter RL, Stephenson C and Wu R. Prolonged PR interval is a risk factor for bradycardia during spinal anesthesia. Reg Anesth. 1995; 20:41-4. | Article | PubMed

8. Sharma SK, Gajraj NM and Sidawi JE. Prevention of hypotension during spinal anesthesia: a comparison of intravascular administration of hetastarch versus lactated Ringer's solution. Anesth Analg. 1997; 84:111-4. | Article | PubMed

9. Brooker RF, Butterworth JFt, Kitzman DW, Berman JM, Kashtan HI and McKinley AC. Treatment of hypotension after hyperbaric tetracaine spinal anesthesia. A randomized, double-blind, cross-over comparison of phenylephrine and epinephrine. Anesthesiology. 1997; 86:797-805. | Article | PubMed

10. Critchley LA and Conway F. Hypotension during subarachnoid anaesthesia: haemodynamic effects of colloid and metaraminol. Br J Anaesth. 1996; 76:734-6. | Article I PubMed

11. Emmett RS, Cyna AM, Andrew M and Simmons SW. Techniques for preventing hypotension during spinal anaesthesia for caesarean section. Cochrane Database Syst Rev. 2002; CD002251. I Article I PubMed

12. Coe $A J$ and Revanas $B$. Is crystalloid preloading useful in spinal anaesthesia in the elderly? Anaesthesia. 1990; 45:241-3. | Article | PubMed

13. McCrae AF and Wildsmith JA. Prevention and treatment of hypotension during central neural block. Br J Anaesth. 1993; 70:672-80. | Article | PubMed

14. Rout CC, Rocke DA and Gouws E. Leg elevation and wrapping in the prevention of hypotension following spinal anaesthesia for elective caesarean section. Anaesthesia. 1993; 48:304-8. | Article | PubMed

15. Lim HH, Ho KM, Choi WY, Teoh GS and Chiu KY. The use of intravenous atropine after a saline infusion in the prevention of spinal anesthesiainduced hypotension in elderly patients. Anesth Analg. 2000; 91:1203-6. | Article I PubMed

16. PUN Nze. Effect of Pre-medication with Atropine on the Blood Pressure of Parturient Undergoing Caesarian Section under Spinal Anaesthesia. Orient Journal of Medicine. 2003; 15:1-4. | Article

17. Hirabayashi Y, Saitoh K, Fukuda H and Shimizu R. [Atropine has little significance as a premedication for spinal anesthesia]. Masui. 1994; 43:306-10. | Article | PubMed

18. Ure D, James KS, McNeill M and Booth JV. Glycopyrrolate reduces nausea during spinal anaesthesia for caesarean section without affecting neonatal outcome. Br J Anaesth. 1999; 82:277-9. | Article | PubMed

\section{Citation:}

Sigdel S. Prophylactic use of IV atropine for prevention of spinal anesthesia induced hypotension and bradycardia in elderly: a randomized controlled trial. J Anesthesiol Clin Sci. 2015; 4:5.

http://dx.doi.org/10.7243/2049-9752-4-5 